phesied that in ten years there would be more fatalities from carcinoma than from consumption, small-pox, and typhoid fever combined. This in human beings! How stands the matter among the domesticated animals? A worthy subject of inquiry surely.

\title{
CASES OF ANTHRAX WITHOUT MARKED ELEVATION OF TEMPERATURE.
}

\author{
By G. H. Gibbings, F.R.C.V.S., Tavistock.
}

I REGARD the veterinary surgeon who is called to a case of anthrax prior to death as singularly unfortunate, especially if he is a stranger to the district.

The symptoms of the disease are so obscure and variable that even the most experienced and careful practitioner is liable to err.

The most constant indication of anthrax in cattle is the presence of small clots of dark-coloured blood mixed with rather loose faces, and this is usually associated with a high temperature, but the latter is not essential when the animal is visibly ill. I do not dispute the value of the thermometer in diagnosing the disease during its incubative period; but when the bullock is in such a condition that the owner seeks the services of the veterinary surgeon, then too much reliance 'should not be attached to what may be termed the negative evidence of the temperature.

A few years ago I was requested to attend a cow. On my arrival at the farm the owner stated she had refused her food in the morning, but now appeared much better and had just devoured a couple of mangolds.

As prior outbreaks of anthrax had occurred on this farm, I was particularly careful in my examination. The fæces were dark in colour, rather fluid, and stained with blood. The cow had a depressed appearance, but to my great astonishment the temperature was only ${ }^{10} 3^{\circ} \mathrm{F}$. After prescribing for the animal, I requested the owner to report to me the following morning. The same evening I received a message stating that the cow died a couple of hours after I left the premises.

I made a post-mortem, and found it to be a typical case of anthrax.

In this case I was altogether misled by the thermometer, and had I left this precious instrument at home I should certainly have warned the owner of my suspicions.

The latter end of April I received a hurried message from a poor man stating both of his cows were very ill. I found one dead, and the appearance of the carcase was very suspicious of anthrax. A portion of the ear was forwarded to Prof. $M^{\prime}$ Fadyean, and the reply came "undoubtedly anthrax."

The other cow located in the same shed refused all food, was scouring profusely, stiff in her gait, and grunted occasionally during movement. Temperature only $102^{\circ} \mathrm{F}$. She gradually improved and was convalescent in a week.

I know it may be argued there is no positive proof of the existence of anthrax in this cow, but, considering these were the only two cows 
the owner possessed, that they were fed alike, grazed in the same pasture, and were in close contact in the shed, it would be rather a remarkable coincidence if she were the subject of any other disease.

\title{
A CASE OF BOTRYOMYCOSIS, OPERATION AND RECOVERY.
}

\author{
By Arthur R. Routledge, F.R.C.V.S., London.
}

Subject.-A brown van mare, about fourteen years old.

History.-For the last three years has had a growth in front of and slightly below the elbow joint, gradually increasing in size. When first observed the tumour was about the size and shape of a tomato, hard, painless, and freely movable, and seemed to invade the skin and subcutaneous tissue only.

The hair over the affected area was scanty, bristly, and erect. The skin studded with small elevations about the size of a bean, which came up as boils, burst, and healed up, leaving a fibrous thickening, or being replaced by other small abscesses.

Occasionally the growth became rapidly larger, and the abscesses were lanced and a biniodide of mercury blister applied, when a slight temporary reduction took place, only to be followed by progressive increase in size.

Eventually the tumour obtained the size of a turnip, and so interfered with the action of the extensors of the forearm as to cause lameness.

Diagnosis.-Botryomycosis.

Operative treatment the only means of relief.

On Ist November 1902 the mare was cast, chloroformed, and the growth removed with antiseptic precautions.

Operation.-An elliptical incision including the affected skin was made, and the tumour dissected from the face of the extensor muscles. During excision two large abscesses in the depths of the growth, each containing about 4 ozs. of pus, were accidentally evacuated.

The edges of the wound were approximated as far as possible by seven tape sutures, which had to be taken out on the seventh day, as they were cutting through the skin and becoming embedded in the muscles, causing excessive granulation.

The wound was dressed with chinosol I: 500 , alternated with carbolic acid $I: 40$, chloride of szinc $I: 40$, or liq. antim. chlor., as circumstances indicated.

There was considerable discharge, which by i $5^{\text {th }}$ November was reduced to a minimum, and the wound from this date made an uninterrupted recovery.

The mare was in slings for about a month, and resumed work 9th February, having been under treatment fourteen weeks.

The tumour, which weighed 3 lbs. 2 ozs., was sent to Prof. M'Fadyean, and he confirmed the diagnosis.

$\mathrm{Up}$ to the time of writing (June 1903) the mare has been at regular work, and there has been no evidence of recurrence. 